\title{
Attitude to Authority and Digital Competences of Bulgarian Preschool Teacher's
}

\author{
Nadezhda Angelova Kaloyanova \\ University "Prof. d-r Assen Zlatarov”, Burgas, Bulgaria
}

\begin{abstract}
.
The thesis of this study is based on the assumption that the authority of the teacher manifests as a specific status or professional role and should be internalized in his overall professional profile. This type authority is defined "a formal authority" and is strongly influenced by the requirements of the educational environment (social aspect) and the specific professional competences of the teacher (individual aspect). The attitude of the teachers towards they own authority, which implements the set of professional roles and competences, is a prerequisite for the formation and manifestation of an adequate professional model, which directly influences the quality and culture of the educational environment. In this study attitudes towards teachers' own authority are examined in relation to one of the teacher's current professional competencies - the digital competence. The study uses the concept of liberalism conservatism to explain the nature of the social manifestation and experiencing of teacher's own authority in terms of his status-role model, defined as a liberal authority or as a conservative authority. The research is performed with two scales, which are separately developed sets of statements. The first scale - „Attitude to Authority” - is an adapted and integrative version of the established standardized „Attitude to Authority Scale“(Ray, 1971) and GAIAS (Rigby, 1982). The second scale, "Digital Competence", was developed as an integrative scale to explore teachers' attitudes towards digitalization of education and to study specific skills involved in digital competence. The both Scale are nominal (Likert) type. Research involve 202 Bulgarian preschool teachers. The results are analysed in three stages: Evaluation of the Scales internal consistency; Factor Analyse and Correlation Analyses. The general conclusion of the study is, that the teachers demonstrate a high degree of digital competence, which is combined with moderate, still tending (in some essential aspects) to conservative authority. That calls into question the effective internalization of this key competence in the professional model of respondents.
\end{abstract}

Keywords: attitude to authority, digital competences, preschool teachers, professional roles

\section{Introduction}

"Authority "is a term that is widely used in the social sciences and humanities, which is discussed in two related aspects. As a specific status of personality, "authority" means the right to exercise power and influence. However, this right is not identical with power and obedience. Authorities are individuals of high social prestige who are important to other 


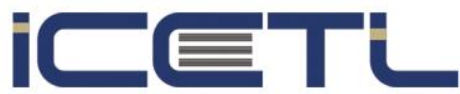

21-23 FEBRUARY, 2020

\section{$3^{\text {rd }}$ International Conference on Research in EDUCATION, TEACHING and LEARNING}

ROME, ITALY

people. To such personalities qualities are attributed - knowledge, skills, abilities that are valuable to others. High expectations are expressed by others to them and they are respected, regarded and recognized in smaller, larger communities or in society. (Ivanov, 1995). This kind of authority is defined as ,individual authority“ (Ivanov, 1995; Piryov, 1975; Ivanov, 1985; Shibutany, 1969; Reber, 1985; Fotev, 1987).

In another aspect, authority also has a certain social expression which, according to Max Weber, is highly dependent on the current social paradigm. In defining the types of authority, Weber attributes the rational-legal authority to increasingly bureaucratic and rationalized societies. This thesis, which is still valid today, constitutes formal authority as a meaningful individual construct, manifested at three levels: the social, the community and the intra-group. (Georgiev, 91, p. 102-103).

In theories of power, authority is viewed in two main varieties: formal and informal authority. According to some authors (J. Adams, A. Romney, G. Homans), informal authority is primary, able to explain the formal, and according to other authors, these are two independently existing constructs related to different social roles that integrate into the person, forming its whole authority (Ivanov, 1995).

Formal authority is mostly provided by the authority of the professional position. It forms around 65\% impact on subordinates. Moral authority depends mainly on the moral qualities of the leader, and functional is determined by the professional competence business qualities and attitude to work of the leader, Moral and functional authority account for $45 \%$ of total authority of the person (Kriviradeva, 2018).

Understanding and study of authority at the group (social) and personal (individual) levels at the same time, and its strong dependence on social relations and the situation in which it exists, reinforces the notion of "Attitude to authority". Attitude is a concept in social psychology and represents "an organized predisposition to responding in a favorable or unfavorable direction to a specific class of social objects" (according to Dzhonev, 1996; p. 213), "an unconscious form of stimulation of the psycho-behavioral activity of an individual, acquired in individual experience and it is provoked by a certain type of situations" (Minchev, 2006; p. 101). Attitudes directly influence an individual's behavior. Combining the social and the psychological, attitudes are both a functional component of The Ego and an integral part of the individual's value system (Dzhonev, 1996; Minchev, 2006; Andreeva, 1983).

The importance of studying attitudes is emphasized by a number of authors in different scientific contexts, since analyzing attitudes means determining the whole person's concern (feelings, appraisals and tendencies to approach / avoid) to focal objects (Scott, 1954). A significant number of scholars see the benefit of studying attitudes to understand and predict trends in the development of significant social tendencies such as prejudice, environmental protection, educational development, and public understanding of science (Allport, 1954; Tajfel, 1981; Dunlap \& Jones, 2002; Pampaka et al., 2012; Sturgis et al., 2010).

In the same context, other authors emphasize the importance of exploring attitudes to understand the mechanisms of formation and changing public opinion, and more generally their impact on important social problems, such as civic participation and participation in the cultural sphere of society as a whole (Elliott et al. 2014; Dinas, 2013; Zaller, 1987, 1992; Green et al., 2006; Paterson, 2008). There are also authors who define attitudes as an essential part, the core of a culture or certain subcultures (Fernandez \& Fogley, 2009; Inglehart, 1997; 


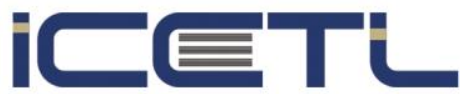

21-23 FEBRUARY, 2020

\section{$3^{\text {rd }}$ International Conference on Research in EDUCATION, TEACHING and LEARNING}

ROME, ITALY

Heath \& Payne, 2000; Bisin \& Verdier, 2011; Bourdieu \& Passeron, 1977; Bronfenbrenner, 1979).

In this sense, the attitude towards authority is defined as "support or opposition for the subordination of individual freedom and autonomy to the collective and its authority" (Duckitt \& Bizumic, 2013, p. 843)

In this study, the term Authority is used in the context of education as a social system. This concept explains the social influence of educational institutions and teachers as their representatives, as well as the corresponding power, which legitimizes this influence. In the same context, attitudes toward authority represent attitudes toward power as positive or negative evaluations of control and sanctions applied by the educational system and its institutions to its members.

The need to study attitudes to authority in education, and in particular to teachers, is emphasized by authors who traditionally explore attitudes toward authority, because recognizing the authority of educational institutions would greatly support the understanding of attitudes toward institutional authority in general (Rigby et al., 1984, 1987; Dornbusch \& Scott, 1975; Dunbar \& Taylor, 1982; Gumbert et al., 1981)

The thesis of this study is based on the assumption that the authority of the teacher manifests as a specific status or professional role and should be internalized in his overall professional profile (Kaloyanova \& Ivanova, 2010). The teacher's role-playing authority is viewed as "... the inherent essence of his legitimate authority, recognition of his right to make responsible decisions in situations of co-activity that are meaningful to the student" (Ivanov, 1995, p. 99). This type authority is defined "a formal authority" and is strongly influenced by the requirements of the educational environment (social aspect) and the specific professional competences of the teacher (individual aspect). The attitude of the teachers towards they own authority, which implements the set of professional roles and competences, is a prerequisite for the formation and manifestation of an adequate professional model, which directly influences the quality and culture of the educational environment.

Since there are now two main approaches to classifying people's social beliefs: liberalismconservatism (Jost et al., 2009) and liberalism-authoritarianism (Duckitt \& Bizumic, 2013), this study uses the concept of liberalism - conservatism. This concept explains the nature of the social manifestation and experience of the teacher's own authority in terms of his statusrole model, exactly - as directed to freedom, shortening distance and flexibility (liberal authority), or as centered in tradition, power and directive interactions (conservative authority).

In this study attitudes towards teachers own authority are examined in relation to one of the teacher's current professional competencies - the digital competence. The digital competence of the teacher is being considered as "... the ability to use ICT with a good pedagogicaldidactic ICT understanding and to be aware of how this might impact the learning strategies and educational formation of pupils" (Krumsvik, 2007, p. 68).

The digital competence of teachers also includes knowledge and attitudes to using ICT, various softwares and on-line based information, with a critical attitude towards the quality of resources and information, as well as the activation of problem-solving skills (Ilomäki et al., 2011; Krumsvik, 2011, 2012; Käck \& Männikkö Barbutiu, 2012). 


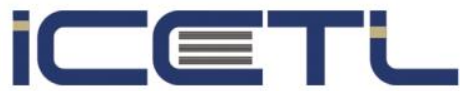

21-23 FEBRUARY, 2020

\section{$3^{\text {rd }}$ International Conference on Research in EDUCATION, TEACHING and LEARNING}

ROME, ITALY

From this point of view, five basic skills are considered as the basic structural components of digital competence: Information and data literacy, Communication and collaboration, Digital content creation, Safety and Problem Solving (Carretero, St. et al., p.11).

In this research, digital competence is studied not only in aspect of the five included basic skills, but also with regard to teachers' attitudes towards digitalization of education, since competence itself requires as a prerequisite the presence of such an attitude, on the one hand, and - attitudes toward professional role-playing authority are influenced precisely by specific attitudes toward particular competencies.

\section{Methods}

The study is realized by using two scales, which are separately developed sets of statements. The first scale - „Attitude to Authority“ is an adapted and integrative version of the established standardized „Attutude to Authority Scale“ (Ray, 1971) and GAIAS (Rigby, 1982).

The scale contains three sub scales. The sum of all items in the scale totals 24 .

Sub-Set 1: "Leadership: executive vs. decision maker" includes items 1 to 8

Sub-Set 2: "Institutional Athority: delegation vs. force" includes items 9 to 16

Sub-Set 3: "Pedagogical Interaction: Freedom vs. Regulation" includes items 17 to 24

Each one Sub-scale contains 8 items.

All items are scored from 4 to 1, as 4 (Strongly agree), 3 (Agree), 4 (Disagree), 1 (Strongly disagree). The sum of the scores is interpreted by 3 scales of referent values according to 3 different type of Authority - Liberal, Medium and Conservative (Tabl.1).

Table 1: Referent Values of Authority Type

\begin{tabular}{|l|l|l|l|l|}
\hline $\begin{array}{l}\text { Type of } \\
\text { Authority }\end{array}$ & Leadership & $\begin{array}{l}\text { Institutional } \\
\text { Authority }\end{array}$ & $\begin{array}{l}\text { Pedagogical } \\
\text { Interaction }\end{array}$ & Total \\
\hline Liberal & $32-24$ & $32-24$ & $32-24$ & $96-72$ \\
\hline Medium & $23-15$ & $23-15$ & $23-15$ & $71-49$ \\
\hline Conservative & $14-8$ and up & $14-8$ and up & $14-8$ and up & $48-24$ and up \\
\hline
\end{tabular}

The second scale, "Digital Competence", is developed as a integrative scale to explore teachers' attitudes towards digitalization of education and to study specific skills involved in digital competence, combined into three criteria: Information and data literacy and Digital content creation; Communication and collaboration; Safety and Problem Solving.

The scale contains 4 subscales:

Sub-scale 1: Attitudes towards digitalization of education - includes items 1 to 10

Sub-Scale 2: Collecting and Arranging Information and Creating Educational Content (Information and Content) - includes items 11 to 20

Sub-Scale 3: Communicating with Students, Colleagues and Parents (Communication) includes items 21 to 25

Sub-Scale 4: Safety and Problem Solving in an Educational Context (Safety and Problem Solving) - includes items 26 to 30 
Analogically, the items are scored from 4 to 1 , as 4 (Strongly agree), 3 (Agree), 4 (Disagree), 1 (Strongly disagree). The sum of the scores is interpreted by 4 scales of referent values according to 3 different levels- High, Average and Low (Tabl.2).

Table 2: Referent Values of Digital Competence

\begin{tabular}{|l|l|l|l|l|l|}
\hline Level & $\begin{array}{l}\text { Attitude to } \\
\text { Digitalization }\end{array}$ & $\begin{array}{l}\text { Information and } \\
\text { Content }\end{array}$ & Communication & $\begin{array}{l}\text { Security and } \\
\text { Problem Solving }\end{array}$ & Total \\
\hline High & $40-30$ & $4,0-30$ & $20-15$ & $20-15$ & $120-90$ \\
\hline Average & $29-19$ & $29-19$ & $14-11$ & $14-11$ & $89-59$ \\
\hline Low & $20-10$ and up & $20-10$ and up & $10-5$ and up & $10-5$ and up & $60-50$ and up \\
\hline
\end{tabular}

Research involve 202 preschool teachers from Bulgarian educational system. 199 teachers are femail, and 3 - mail. 5\% are under 25 age; 9,4\% - between 26-30 age; 32,7\% - between $31-45$ age; $29,2 \%$ - between $46-55$ age and 23,8\% - over 55 age. $74,3 \%$ work in Kidergartens in big towns, $20,8 \%$ - in small towns and 4,9\% - in villages.

The results are analysed in three stages:

- Evaluation of the Scales internal consistency by the Cronbach Alpha Consistency Assessment procedure (Cronbach, 1988);

- Factor Analyse - KMO and Bartlett's Test and extraction of the main Factors;

- Correlation Analyses with Pearson linear correlation coefficient (r).

\section{Results and Discussion}

\subsection{Evaluation of the Scales internal consistency}

Internal consistency of items is evaluated by the Cronbach Alpha Consistency Assessment procedure. Alpha Cronbach's Values are shown below (Cronbach, 1988):
$0,9-1,0$
Excellent
$0,8-0,9$
Very good
$0,7-0,8$
Good for practical purposes
$0,6-0,7$
Modest
0,6 and down Miserable

The results for both scales and their subscales are shown in a Table 3.

Table 3: Cronbach's Alpha of Scales and their Sub-scales

\begin{tabular}{|l|l|c|c|r|c|}
\hline Scales & Sub Scales & $\mathrm{K}$ & $\alpha$ & corr & $\alpha$ \\
\hline Attitude to Authority & Leadership & 8 &, 299 &, 127 & \\
\cline { 2 - 5 } & Institutional Authority & 8 &, 219 &, 084 & \multirow{5}{*}{, 529} \\
\cline { 2 - 5 } & Pedagogical Interaction & 8 &, 347 & & \\
\hline Digital Competence & Attitude to Digitalization & 10 &, 868 &, 589 & \\
\cline { 2 - 5 } & Information and Content & 10 &, 721 & & \multirow{3}{*}{, 857} \\
\cline { 2 - 5 } & Communication & 5 &, 672 &, 434 & \\
\cline { 2 - 5 } & Security and Problem Solving & 5 &, 544 &, 316 & \\
\hline
\end{tabular}




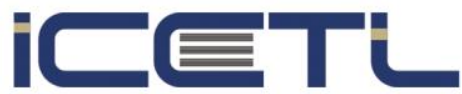

21-23 FEBRUARY, 2020

\section{$3^{\text {rd }}$ International Conference on Research in EDUCATION, TEACHING and LEARNING}

ROME, ITALY

In general, the Cronbach coefficient $\alpha$ is characterized by great variability on the Digital Competence scale. It ranges from 0.544 (Safety and Problem Solving subscale) to 0.868 (Attitudes to Digitalization subscale), with a total scale of 0.857 . This means that, generally for scales of digital competence, alpha is acceptable to high values, i.e. the teachers surveyed showed a high degree of consistency in their opinions, especially regarding the attitudes towards digitalization. In the Subscale Attitudes to Digitalization, the most heavily embedded item is Laptops, tablets and other digital devices substantially impaired by the teacher's work 0.731 , and the least implied is It is better to educate students/children to use smartphones to study than to prohibit their use in school /kindergarten - 0.358. The mean score is 79.34 , which falls within the medium levels according to Table 1 .

The conclusion is that the respondents strongly demonstrate conditionally moderate attitudes towards digitalization of education. However, their competence to solve problems and maintain security in a digital educational environment is unsustainable and variable. Proof of this is the fact that in the Digital Competence scale, the least included are the three items that belong to the Subscale Safety and Problem Solving. These are the items: In the internet communication, I demand that the established "netiquette" should be observed - 0.319; If I use digital technology during class and have a crash, I can safely continue, even if I can't solve the problem - 0.313; I constantly warn pupils / children about dangers on the Internet and take preventative steps - 0.333

The Attitude to Authority Scale is characterized by a low consistency that is at the limit of acceptable Cronbach's alpha values. The internal consistency of the individual subscales is unacceptable. Particularly disturbing are the low levels of consistency at the Subscale Institutional Authority, where 5 items are practically zero in size. These are the items There's generally a good reason for every rule and regulation in the educational system, but strict adberence is sometimes not possible - 0.009; It would be much better if education is free from centralized policies - 0.054; The state is not obliged to protect the authority of the teacher 0 , 083; I feel like an authoritative teacher, despite the view that contemporary teachers are inmature and ignored -0.071 ; When it comes to protecting his / her own authority, it is the teacher's responsibility -0.076 . The average score of the respondents on this scale is 10.6 , which is a demonstration of extreme conservatism. The conclusion may be that preschool teachers' perceptions of institutional freedom and delegation of powers in the educational environment are too diverse, but in general they still recognize coercion and power as legitimate authority.

\subsection{Factor Analyses - extraction of the main Factors}

Because the Cronbach's alpha reliability assessment has showed instability across the two subscales of the both scales, factor analysis aims to isolate only the main factors and show the subscales belonging to them. The second objective is that the both scales align their indicators to allow correlation analysis.

The latent structure of the Attitude to Authority scale indicates refraction in the second component (Fig. 1). 
Figure 1: Latent structure of Attitude to Authority Scale

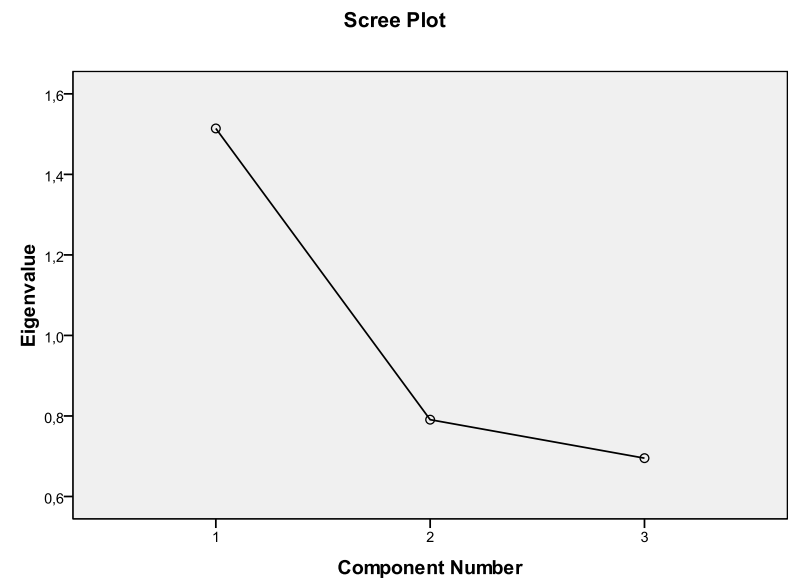

This means that it is acceptable to admit a two-component factor matrix (Tabl. 4).

After statistical processing of the scale data by rotation of the component matrix, two main factors were formed. The first factor covers the Leadership subscale and the Institutional authority subscale, and the second includes the Pedagogical interaction subscale. The overall reliability of the scale increased - the Kaiser-Mayer-Olkin coefficient was 0.604 (Tabl. 5). His interpretation is similar to Cronbach's alpha. In this case, the authority scale is considered modest.

Table 4: Rotated Component Matrix ${ }^{\mathrm{a}}$ of Attitude to Authority Scale

\begin{tabular}{|l|r|r|}
\hline & \multicolumn{2}{|l|}{ Component } \\
\cline { 2 - 3 } &, 917 & \\
\hline scaleleader &, 591 & \\
scaleinst & &, 945 \\
scaleped & & \\
\hline
\end{tabular}

Extraction Method: Principal component

Analysis.

Rotation Method: Varimax with Kaiser

Normalization.

a. Rotation converged in 3 iterations.

Table 5: KMO and Bartlett's Test (Attitude to educational Authority Scale)

\begin{tabular}{|ll|r|}
\hline Kaiser-Meyer-Olkin Measure of Sampling Adequacy. &, 604 \\
Bartlett's Test of Sphericity & Approx. Chi-Square & 36,556 \\
& df & 3 \\
Sig. &, 000 \\
\hline
\end{tabular}


The Digital Competence Scale also created two factors, the first combining the subscales Attitude to Digitalization, Information and Content, and Communication. The second involves Subscale Safety and Problem Solving (Tabl. 6).

Table 6: Component Matrix ${ }^{\text {a of }}$ Attitude to Digitl Competence Scale

\begin{tabular}{|l|r|r|}
\hline & \multicolumn{2}{|l|}{ Component } \\
\cline { 2 - 3 } & 1 & 2 \\
\hline scaled1 &, 706 & \\
scaled2 &, 873 & \\
scaled3 &, 727 & \\
scaled4 & &, 851 \\
\hline \multicolumn{2}{|l|}{ Extraction Method: Principal }
\end{tabular}

Component Analysis.

a. 2 components extracted.

The latent structure of the Attitude to Digitalization Scale also indicates refraction in the second component (Fig. 2). After the statistical procedure KMO and Bartlett's Test the both scales align their indicators (Tabl. 7) .

Table 7: KMO and Bartlett's Test (Digital Competence Scale)

\begin{tabular}{|ll|r|}
\hline Kaiser-Meyer-Olkin Measure of Sampling Adequacy. &, 606 \\
Bartlett's Test of Sphericity & Approx. Chi-Square & 145,339 \\
& df & 6 \\
& Sig. &, 000 \\
\hline
\end{tabular}

Figure 2: Latent structure of Digidal Competences Scale

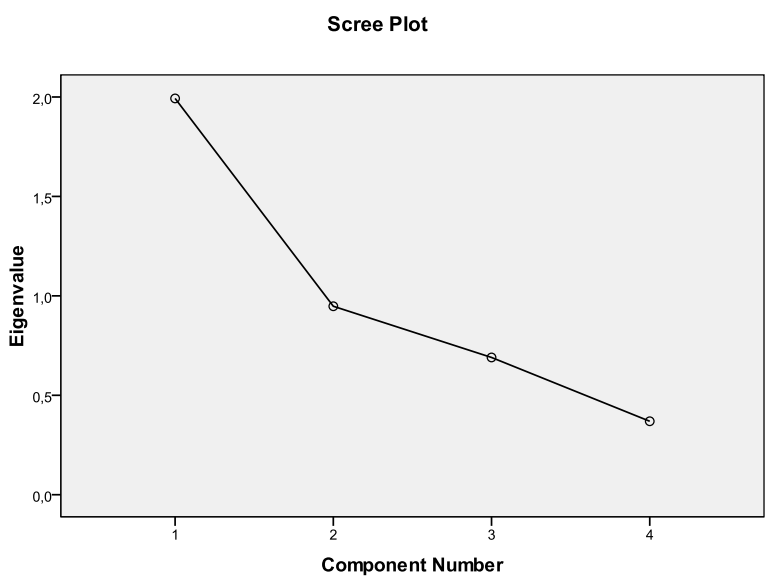

Factor analysis allows to continue with correlation analysis under the following conditions: 
- The two scales have a homogeneous structure;

- Their subscales are about two factors;

- Their reliability coefficient after factor analysis is relatively equal and modest.

\subsection{Correlation Analyse}

Under the above conditions, correlation analysis is only possible if the both scales are characterized by a normal data distribution. The following histograms make it clear that the distribution in the both main scales is relatively uniform et allows correlation to be derived using the Pearce coefficient (Fig. 3).

Figure 3: Data distribution in the main Scales
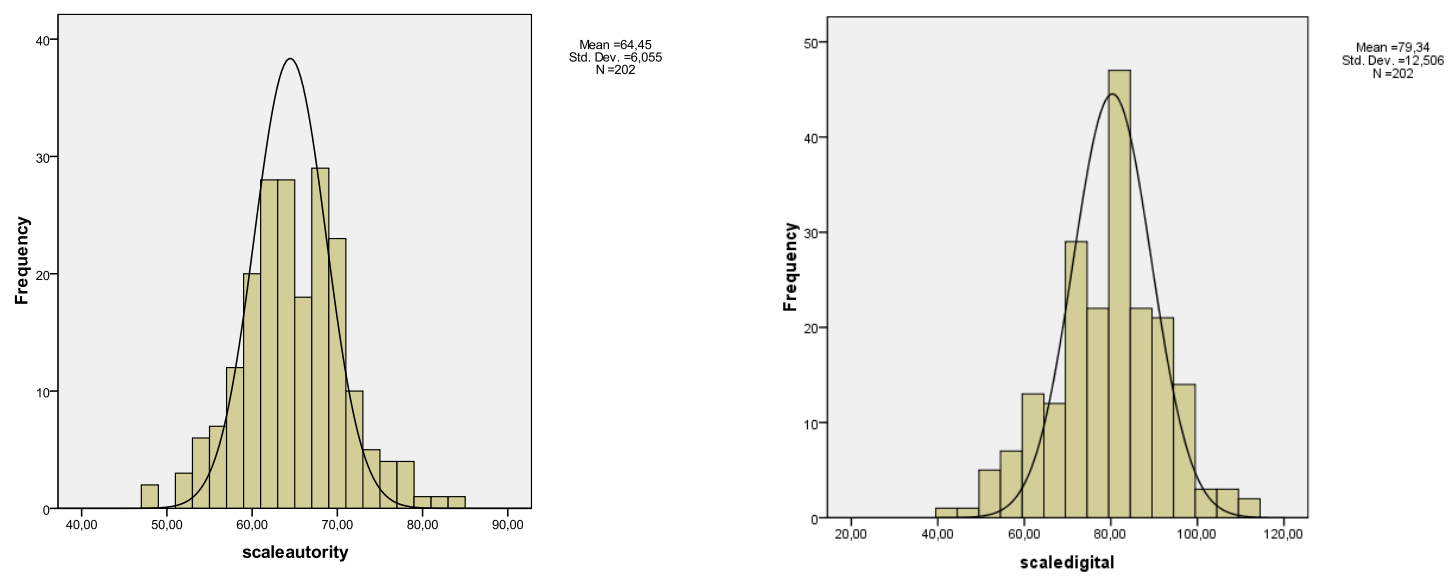

In this case, a correlation between the two scales could be clearly identified, i.e. to determine the relationship between the attitudes towards authority and the digital competence of the respondents. The Table 8 shows that there is a positive correlation, though a weak correlation -0.212 (Tabl. 8). This suggests that the high values of digital competence will be mainly related to liberal authority.

Where such correlation exists, it should be determined how it is characterized. For this purpose, the average values of respondents who showed high digital competence (between 90 and 120) will be compared with the average values of the same respondents on the Attitudes to Authority Scale (Tabl. 1 and Tabl. 2)

Table 8. Correlations between Attitude to Authority Scale and Digital Competence Scale

\begin{tabular}{|ll|l|l|}
\hline scaleautority & scaleautority & scaledigital \\
& Pearson Correlation & 1 &, $212^{* *}$ \\
& Sig. (2-tailed) & &, 002 \\
& $\mathrm{~N}$ & 202 & 202 \\
\hline scaledigital & Pearson Correlation &, $212^{* *}$ & 1 \\
& Sig. (2-tailed) &, 002 & \\
& $\mathrm{~N}$ & 202 & 202 \\
\hline
\end{tabular}

**. Correlation is significant at the 0.01 level (2-tailed). 
The average on the Digital Competence Scale is high with 46 respondents. Their average score is 95.76 , i.e. just above the lower limits of the high reference values. The average score of the same respondents on the Attitude to Authority Scale is 66.64 - a stable moderate value.

The result shows that digital competence is well formed, while attitudes toward authority are almost relevant to values throughout the research sample $(x=64.45$ at $n=220 ; x=66.64$, at $\mathrm{n}=46$ ).

After establishing the normality of distribution in the digital competence subscales, a correlation analysis is made between the different subscales in the both major scales (Fig.4).

Figure 4. Data distribution in the Subscales Pedagogical Interaction and Attitude to Digitalization
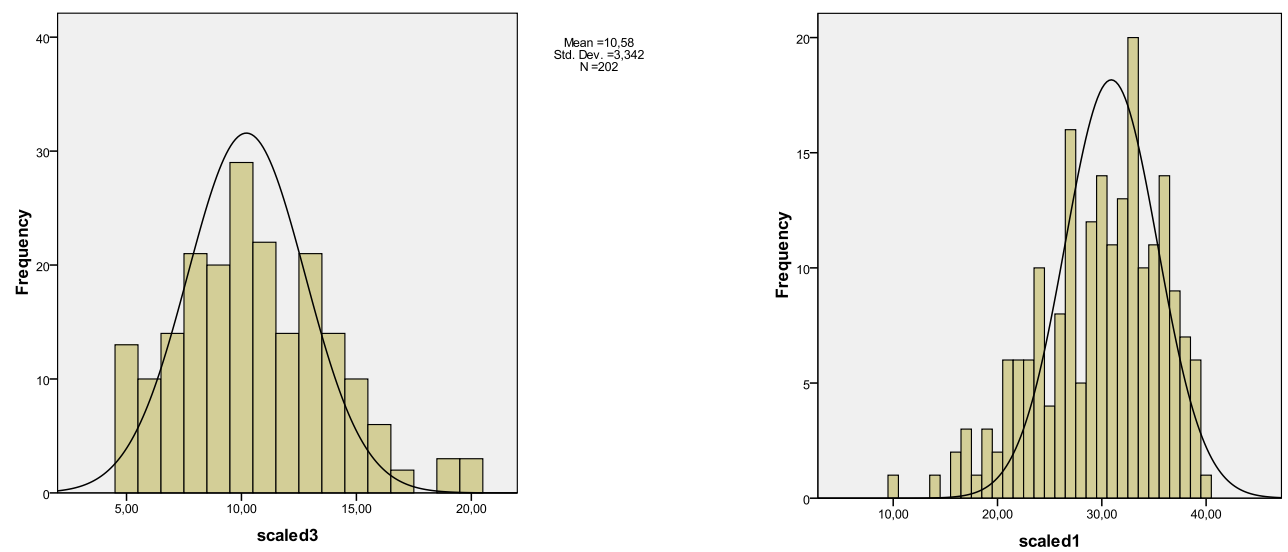

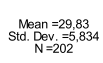

Correlation analysis shows the following correlations between the subscales in the both scales:

- Subscale Leadership correlates poorly with two subscales of the digital competence scale: subscale 1 Attitudes toward digitalization in education and Subscale 4: Safety and problem solving (Tabl. 9).

The average score in the Leadership subscale was 19.81 , i.e. in moderate values of authority type.

The average score on the digitalization attitudes subscale is 29.83 , i.e. at the limit of high reference values.

The average score in the Safety and Problem solving subscale is 14.73 - also at the high reference limit.

With these ratios found, the more definite conclusion may be that the attitudes towards digitalization are combined with a moderate manifestations of authoritative leadership. The relation "Leadership" - "Safety and problem solving" in the digital educational environment cannot be determined with such categorization, despite the high average scores on the digital competence scale, as the Safety and Problem solving subscale belongs to a separate factor and demonstrates a weak latent structure. 
Table 9. Correlations between Subscales in both Scales

\begin{tabular}{|c|c|c|c|c|c|c|c|c|}
\hline & & scaleleader & scaleinst & scaleped & scaled 1 & scaled2 & scaled 3 & scaled4 \\
\hline \multirow[t]{3}{*}{ scaleleader } & $\begin{array}{l}\text { Pearson } \\
\text { Correlation }\end{array}$ & 1 &, $285^{* *}$ &, $210^{* *}$ &, $193^{* *}$ &, 096 &,- 007 &, $164^{*}$ \\
\hline & Sig. (2-tailed) & & ,000 & ,003 & ,006 &, 173 & ,922 & ,020 \\
\hline & $\mathrm{N}$ & 202 & 202 & 202 & 202 & 202 & 202 & 202 \\
\hline \multirow[t]{3}{*}{ scaleinst } & $\begin{array}{l}\text { Pearson } \\
\text { Correlation }\end{array}$ &, $285^{* *}$ & 1 &, $274^{* *}$ &, 085 & ,087 & ,209** &,- 034 \\
\hline & Sig. (2-tailed) &, 000 & & ,000 & ,232 & ,219 & ,003 & ,635 \\
\hline & $\mathrm{N}$ & 202 & 202 & 202 & 202 & 202 & 202 & 202 \\
\hline \multirow[t]{3}{*}{ scaleped } & $\begin{array}{l}\text { Pearson } \\
\text { Correlation }\end{array}$ &, $210^{* *}$ &, $274^{* * *}$ & 1 & ,119 &, 106 &, $141^{*}$ & ,101 \\
\hline & Sig. (2-tailed) &, 003 & ,000 & & ,091 & ,132 & ,046 & ,151 \\
\hline & $\mathrm{N}$ & 202 & 202 & 202 & 202 & 202 & 202 & 202 \\
\hline \multirow[t]{3}{*}{ scaled1 } & $\begin{array}{l}\text { Pearson } \\
\text { Correlation }\end{array}$ &, $193^{* *}$ & ,085 & ,119 & 1 &, $458^{* * *}$ &, $295^{* *}$ &, $193^{* * *}$ \\
\hline & Sig. (2-tailed) &, 006 & ,232 & ,091 & &, 000 & ,000 & ,006 \\
\hline & $\mathrm{N}$ & 202 & 202 & 202 & 202 & 202 & 202 & 202 \\
\hline \multirow[t]{3}{*}{ scaled2 } & $\begin{array}{l}\text { Pearson } \\
\text { Correlation }\end{array}$ & ,096 & ,087 & , 106 &, $458^{\text {*** }}$ & 1 &, $557^{* *}$ &, $305^{\text {** }}$ \\
\hline & Sig. (2-tailed) &, 173 & ,219 & , 132 & 000 & &, 000 & ,000 \\
\hline & $\mathrm{N}$ & 202 & 202 & 202 & 202 & 202 & 202 & 202 \\
\hline \multirow[t]{3}{*}{ scaled3 } & $\begin{array}{l}\text { Pearson } \\
\text { Correlation }\end{array}$ &,- 007 & ,209** & , $141^{*}$ &, $295^{* *}$ &, $557^{* *}$ & 1 & ,062 \\
\hline & Sig. (2-tailed) & ,922 & ,003 & ,046 & 000 &, 000 & & ,378 \\
\hline & $\mathrm{N}$ & 202 & 202 & 202 & 202 & 202 & 202 & 202 \\
\hline \multirow[t]{3}{*}{ scaled4 } & $\begin{array}{l}\text { Pearson } \\
\text { Correlation }\end{array}$ & , 164* &,- 034 & ,101 &, $193^{* *}$ &, $305^{* *}$ & ,062 & 1 \\
\hline & Sig. (2-tailed) &, 020 & ,635 &, 151 & ,006 &, 000 & ,378 & \\
\hline & $\mathrm{N}$ & 202 & 202 & 202 & 202 & 202 & 202 & 202 \\
\hline
\end{tabular}

**. Correlation is significant at the 0.01 level (2-tailed)

*. Correlation is significant at the 0.05 level (2-tailed). 9).

- Subscale Institutional authority correlates poorly with subscale 3: Communication (Tabl.

The average score on the subscale Institutional authority is 20.52 , i.e. in moderate values of authority type.

The average score in the subscale Communication is 10.58 , i.e. at the low of the reference values.

- Subscale Pedagogical interaction correlates poorly with subscale 3: Communication (Tabl. 9)

The characteristics of the highlighted ratio are the following: 


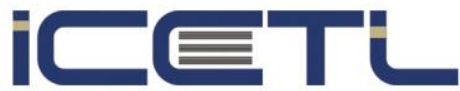

21-23 FEBRUARY, 2020

\section{$3^{\text {rd }}$ International Conference on Research in EDUCATION, TEACHING and LEARNING}

ROME, ITALY

The average score in the subscale Pedagogical interaction is 21.17 , i.e. in moderate values of authority type.

The average score in the subscale Communication is 10.58 i.e. at the low of the reference values.

It can be concluded that the respondents do not sufficiently accept the alternatives that digital technologies offer in communication and are not inclined to use their capabilities in order to liberalize their authority.

\section{Conclusion}

The surveyed preschool teachers show a strong attitude towards digitalization of education, but still unstable specific digital competences. Digital competences are combined with a type of authority that is stable on the border between the liberal and conservative types. In certain situations, conservatism prevails when the authority of preschool teachers is exercised.

Most unstable is the manifestation of competencies for maintaining safety and problem solving, which actually require the teacher not so much traditional knowledge and demonstration of intellectual superiority, but the ability to make mistakes and acknowledge them. It is the perceived resistance to the liberalization of one's own authority that is indicative of the emerging trend, as this part of the digital competence requires a new, liberal realization of the professional role of the authority of the preschool teacher.

Preschool teachers do not yet make full use of electronic communication channels. This shows a distance that continues to be maintained between them and the other participants in the educational process, i.e. again, it is an indication of a conservative rather than a liberal type of authority.

The found tendency that the teachers demonstrate a high degree of digital competence, which is combined with moderate, still tending (in some essential aspects) to conservative authority, calls into question the effective internalization of this key competence in the professional model of respondents.

The findings from previous studies confirm that teachers understand and are motivated to expand their competencies, but still experience a lack of personal resources to delegate rights to other educational subjects and to abandon traditional instructional-directive approaches to interacting in the educational environment.

\section{Acknowledgment}

This paper is an output of the science project "Digital Competencies and Media Education at preschool and primary school age" - DN 05/8 12/14/2016

\section{References}

[1] Andreeva, G., (1983). Social Psychology. Sofia: Science and Art

[2] Jonev, S., (1996). Social Psychology. T. 2. Interaction. Individual. Sofia: SOFI-R

[3] Minchev, B., (2006). Genaral Psychology. Sofia: Siela

[4] Allport, G. W. (1954). The Nature of Prejudice. Cambridge, MA: Addison-Wesley. 


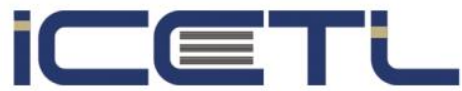

21-23 FEBRUARY, 2020 $3^{\text {rd }}$ International Conference on Research in EDUCATION, TEACHING and LEARNING

ROME, ITALY

[5] Bisin, A., \& Verdier, T. (2011). The economics of cultural transmission and socialisation. Handbook of Social Economics, Vol 1A (pp. 339-416). North-Holland: Elsevier B.V.

[6] Bourdieu, P., \& Passeron, J. C. (1977). Reproduction in Education, Society and Culture. Beverly Hills: Sage.

[7] Bronfenbrenner, U. (1979). The ecology of Human Development. Experiments by Nature and Design. Cambridge (MA): Harvard University Press.

[8] Carretero, St., Vuorikari, R \& Punie. Y, (2017). DigComp 2.1 The Digital Competence Framework for Citizens With eight proficiency levels and examples of use. JRC Science Hub, Luxembourg: Publications Office of the European Union, 2017 () European Union, 2017 [Online]. Available: https://ec.europa.eu/jrc/en/publication/eur-scientificand-technical-research-reports/digcomp-21-digital-competence-framework-citizenseight-proficiency-levels-and-examples-use

[9] Cronbach, L. (1988). Internal consistency of tests: Analyses old and new. // Psychometrika. Vol. 53, No. 1, March, p. 63 - 70).

[10] Dinas, E. (2013). Opening "Openness to Change": political events and the increased sensitivityof young adults. Political Research Quarterly, 20(10), 1-15.

[11] Dornbusch, S. M., \& Scott, W. R. (1975). Education and the exercise of authority. San Francisco, CA: Jossey-Bass.

[12] Duckitt, J., \& Bizumic, B. (2013). Multidimensionality of Right-Wing Authoritarian Attitudes: Authoritarianism-Conservatism-Traditionalism. Political Psychology, 34(6), 841-862.

[13] Dunbar, A. M., \&Taylor, B.W. (1982). Children's per ceptions of elementary teachers as authority figures. Journal of Social Psychology, 118(2), 249-252.

[14] Dunlap, R. E., \& Jones, R. E. (2002). Environmental concern: conceptual and measurement issues. In R. E. Dunlap \& W. Michelson (Eds.), Handbook of Environmental Sociology (pp. 482-524). Westport, CT: Greenwood Press.

[15] Elliot, M., Voas, D., \& Park, A. (2014). Introduction for special section. Attitudes: ontology, methodology, impact. Sociological Research Online, 19(1).

[16] Fernández, R., \& Fogli, A. (2009). Culture: an empirical investigation of beliefs, work and fertility. American Economic Journal: Macroeconomics, 1, 146-177.

[17] Fotev, G., (1987). The theory of social exchange. Sociological Review N 6.

[18] Georgiev, B. (1991). Communities - our home. Sofia

[19] Green, A., Preston, J., \& Janmaat, G. (2006). Education, Equality and Social Cohesion. New York: Palgrave Macmillan.

[20] Gumbert, E. B. (Ed.) (1981). Poverty, power, and authority in education. Atlanta,GE, Atlanta: Georgia State University. 


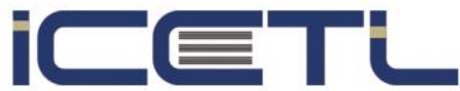

21-23 FEBRUARY, 2020

\section{$3^{\text {rd }}$ International Conference on Research in EDUCATION, TEACHING and LEARNING}

ROME, ITALY

[21] Heath, A., \& Payne, C. (2000). Social mobility. In A. J. Halsey \& J. Webb (Eds.), Twentieth-Century British Social Trends. London: Macmillan.

[22] Ilomäki, L., Kantosalo, A., \& Lakkala, M. (2011). What is digital competence? European schoolnet. Retrieved from http://linked.eun.org/c/document_library/get_file?p_1_id=16319\&folderId=22089\&nam $\underline{\mathrm{e}=\text { DLFE-711.pdf }}$

[23] Ilomäki, L., Kantosalo, A., \& Lakkala, M. (2011). What is digital competence? European schoolnet. Retrieved from http://linked.eun.org/c/document_library/get file?p_lid=16319\&folderId=22089\&nam $\underline{\mathrm{e}=\mathrm{DLFE}-711 . \mathrm{pdf}}$

[24] Inglehart, R. (1997). Modernisation and Post-Modernisation: Cultural, Political and Economic Change in 43 Societies. Princeton, N. J.: Princeton University Press.

[25] Ivanov, D., (1985). Power: philosophical and sociological analysis. Sofia: Science\&Art

[26] Ivanov, I. (1995). The pedagogical power of the teacher. Shumen: ACSIOSS

[27] Jost, J. T., Federico, C. M., \& Napier, J. L. (2009). Political ideology: its structure, functions, and elective affinities. Annual review of psychology, 60, 307-37.

[28] Käck, A. (2012). Digital kompetens i lärarutbildningen. Lund: Studentlitteratur

[29] Käck, A. (2012). Digital kompetens i lärarutbildningen. Lund: Studentlitteratur. Krumsvik, R. A. (2011). Digital competence in Norwegian teacher education and schools. Högre Utbildning, 1(1), 39-51.

[30] Kaloyanova, N., T. Ivanova, (2010). Key Competences and Teacher's Professional Roles. Academical Journal "Management and Education", T.6, B. 1, pp. 248-254

[31] Kriviradeva, B. (2018). Leadership in Educational Institutions. Kriviradeva, B., Kaloyanova, N. Leadership, Organisational Culture and Mentoring in Educational Institucions, 2018, Burgas: LibraScorp, pp. 7-78

[32] Krumsvik, R. (ed.) (2007) Skulen og den digitale læringsrevolusjon [The School and the Digital Learning Revolution; in Norwegian]. Oslo, Universitetsforlaget.

[33] Krumsvik, R. A. (2012). Teacher educators' digital competence. Scandinavian Journal of Educational Research, 1-12.

[34] Layens, G., A. Fronchac., (1990). Aggression as an interpersonal phenomenon. Group and personality in social psychology: 14 Western European scholars. Sofia, pp. 141161.

[35] Pampaka, M., Williams, J., \& Hutcheson, G. M. (2012). Measuring students' transition into university and its association with learning outcomes. British Educational Research Journal, 38(6), 1041-1071.

[36] Paterson, L. (2008). Political attitudes, social participation and social mobility: a longitudinal analysis. British Journal of Sociology, 59, 413-434.

[37] Piryov, G. (1975). Pedagogical Psychology. Sofia: Science\&Art 


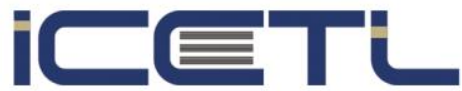

21-23 FEBRUARY, 2020 $3^{\text {rd }}$ International Conference on Research in EDUCATION, TEACHING and LEARNING

[38] Ray, J.J. \& F.H. Lovejoy. (1990). Does Attitude to Authority exist? Personality \& Individual Differences 1990, 11, 765-769.

[39] Ray, J.J. (1971). An "Attitude to Authority" scale. Australian Psychologist, Volume 6 No. 1 March 1971, 31-50.

[40] Reber, A., (1985). The Penguin Dictionary of Psychology. N.Y.,1985.

[41] Rigby, K. (1984). The Attitudes of English and Australian College Students Toward Institutional Authority. The Journal of Social Psychology, 122, 41-48.

[42] Rigby, K. (1984). The attitudes of English and Australian college students towards institutional authority. Journal of Social Psychology, 122, 41-48.

[43] Rigby, K. and Rump, E. E. (1981). Attitudes Towards Parents and Institutional Authority During Adolescence. Journal of Psychology 109: 109-18.

[44] Rigby, K., Schofield, P. and Slee, P. T. (1987). The Similarity of Attitudes Towards Personal and Impersonal Types of authority among adolescent schoolchildren. Journal of Adolescence 10: 241-53.

[45] Schafer, A. Vertrauen: Eine Bestimmung am Beispiel des Lehrer-SchulerVerhaltnisses.- Pad.Runds., 1980, 34, N11.

[46] Scott, W. A. (1954). Attitude measurement. In G. Lindzey \& E. Aronson (Eds.), Handbook of Social Psychology, Volume II (1968th ed.). Reading, MA: AddisonWesley Publishing Company.

[47] Shibutani, T., (1969). Social Psychology. Moskow, 1969.

[48] Sturgis, P., Brunton-Smith, I., \& Fife-Schaw, C. (2010). Public attitudes to genomic science: an experiment in information provision. Public Understanding of Science, (19), $160-180$.

[49] Tajfel, H. (1981). Human Groups and Social Categories. Cambridge: Cambridge University Press.

[50] Vasilev, K., (1978). Social prestige of the individual. Sociological problems of Upbringig. Sofia, pp. 281-296.

[51] Weber, M., (1968). Economy and Society: An Outline of Interpretive Sociology. New York: Bedminster Press.

[52] Zaller, J. R. (1987). Diffusion of political attitudes. Journal of Personality and Social Psychology, 53(5), 821-833.

[53] Zaller, J. R. (1992). The Nature and Origins of Mass Opinion. Cambridge, UK: Cambridge University Press. 